\title{
Fundamental Studies for Application of New Compact
}

\section{Multi-reduction Mill*}

\author{
By Hiroyasu YAMAMOTO,** Toshiyuki SHIRAISHI,** Takao KAWANAMI,*** \\ Sadahiko SHINYA, ${ }^{* 4}$ Takeo GOTO, ${ }^{* 4}$ Toshihiro KOYAMA ${ }^{* 5}$ and Toshimi MINEURA ${ }^{* 6}$
}

\section{Synopsis}

A new compact multi-reduction mill (NCM), which can substitute one stand for two or three stands in a cold tandem mill, has been developed. This new mill is based on a three-pass rolling in one stand and enables a $70 \%$ reduction in thickness in the cold rolling of mild carbon steel. The rolling experiments and numerical calculations showed that a strip-pullingout type NCM rolling was more suitable than a strip-enveloping type $\mathcal{N} C M$ rolling and gave excellent characteristics in rolling lubrication, roll cooling and preventing heat scratch.

Key words: cold rolling; cold rolling mill; lubrication; shape control; gauge control; edge-drop.

\section{Introduction}

An increase of reduction in thickness in a single rolling mill has been demanded recently in order to reduce the number of mill stands and to decrease both the cost of mill construction and the operating cost of rolling. Nippon Steel Corp., IshikawajimaHarima Heavy Industries Co., Ltd. and Toshiba Corp. have developed a new compact multi-reduction mill (NCM) based on three-pass rolling in one stand, which enables a $70 \%$ reduction in thickness in the cold rolling of mild carbon steel. This mill has two variations as shown in Fig. 1. One is a strip-enveloping type NCM and the other is a strip-pullingout type NCM. A strip-enveloping type NGM makes

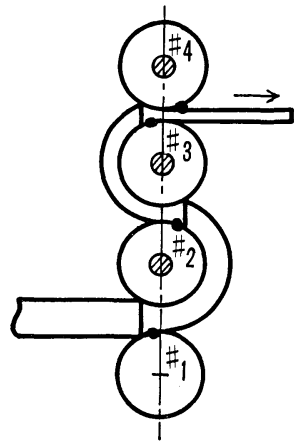

(a) Strip-enveloping type

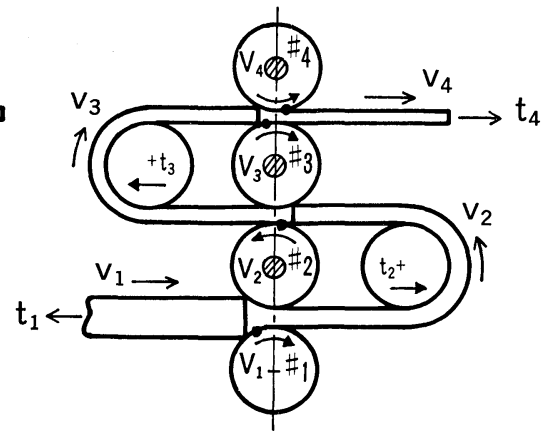

(b) Strip-pulling-out type $t_{1}, t_{2}, t_{3}, t_{4}:$ Strip tensions

Fig. 1. Mill types of NGM rolling. a strip pass around two work rolls, while a strippulling-out type NGM makes a passing strip pulled out by two side-rolls.

Miyasaka et al. ${ }^{1)}$ explain the rolling characteristics of NGM such as rolling load, rolling torque, slip ratio etc. This paper explains the characteristics of NCM rolling with phosphate pre-coating lubrication, automatic gauge controllability, strip shape controllability, characteristics of edge-drop and comparison of NCM rolling types.

\section{Rolling Characteristics and Effects of Phos- phate Pre-coating}

The rolling characteristics of a strip-pulling-out type NCM, and the effects of phosphate pre-coating on rolling stability are explained in this section. Table 1 shows the experimental conditions for NCM rolling mill. The experimental rolling mill is a fourhigh mill with four work rolls of $300 \mathrm{~mm}$ in diameter and $350 \mathrm{~mm}$ in length. Figure 2 shows the experimental rolling mill; The \#2 to \#4 work rolls are driven and the \#1 work roll is non-driven (refer to Fig. 1). The roll speed difference in the second pass $X_{2}\left(=V_{3} / V_{2}-1, V_{3}\right.$ is the peripheral speed of the \#3 work roll, $V_{2}$ is that of the \#2 work roll) can be set up to $0,0.11,0.24$ and 0.35 by changing the gear ratio of the speed reducer. The roll speed difference

Table 1. Experimental conditions of NCM rolling.

1. Work roll size: Diameter: $\phi 300 \mathrm{~mm}$ Length : $\quad 350 \mathrm{~mm}$

2. Driven work rolls: \#2, \#3, \#4 work rolls

3. Rolling method: Strip-pulling-out type Strip-enveloping type

4. Rolling speed $\left(V_{4}\right)$ : Maximum $200 \mathrm{~m} / \mathrm{min}$ Usual $\quad 10 \mathrm{~m} / \mathrm{min}$

5. Roll speed difference

(a) Second pass $X_{2}=V_{3} / V_{2}-1: 0,0.11,0.24,0.35$

(b) Third pass $X_{3}=V_{4} / V_{3}-1: 0 \sim 0.5$

6. Material: Mild carbon steel (SPG)

Thickness : $2.3 \mathrm{~mm}$, Width : $100 \mathrm{~mm}$

7. Lubrication: $6 \%$ emulsion of fat oil, $60^{\circ} \mathrm{G}$

* Based on the paper presented to the 36th Japanese Joint Conferences for the Technology of Plasticity, October 1985, Paper No. 126, The Japan Society for the Technology of Plasticity. Manuscript received on August 26, 1987; accepted in the final form on January 14, 1988 . (C) 1988 ISIJ

** Material Forming Process Research Lab., R \& D Laboratories-III, Nippon Steel Corporation, Edamitsu, Yahatahigashi-ku, Kitakyushu 805.

*** Formerly Material Forming Process Research Lab., R \& D Laboratories-III, Nippon Steel Corporation. Now at Department of Mechanical Engineering, Kanazawa Institute of Technology, Nonoichi-machi, Kanazawa 921.

*4 Research Institute, Ishikawajima-Harima Heavy Industries Co., Ltd., Shinnakahara-cho, Isogo-ku, Yokohama 235.

*5 Heavy Apparatus Laboratory, Toshiba Corp., Toshiba-cho, Fuchu 183.

*6 Fuchu Works Industrial Control System Dept., Toshiba Corp., Toshiba-cho, Fuchu 183. 


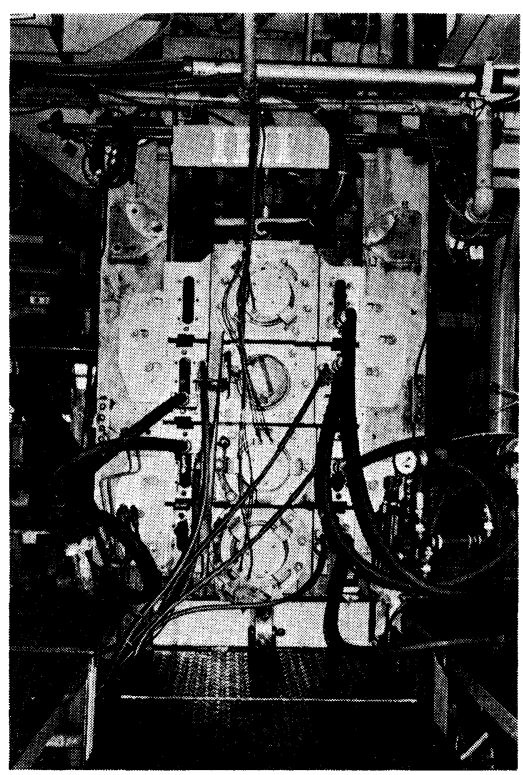

Fig. 2. Experimental new compact multi-reduction mill.

in the third pass $X_{3}\left(=V_{4} / V_{3}-1, V_{4}\right.$ is the peripheral speed of the \#4 work roll) can be changed from 0 to 0.5 because \#3 and \#4 work rolls are driven independently. The amount of phosphate pre-coating on strip surfaces in the case of phosphate pre-coating rolling was 0.3 to $0.6 \mathrm{~g} / \mathrm{m}^{2}$.

Figure $3(\mathrm{a})$ shows the relation between the rolling load and a reduction in thickness in the case with or without phosphate pre-coating, and Fig. 3(b) shows the relation between the rolling energy ${ }^{2)}$ and a reduction in thickness under the same conditions, where $t_{1}$ is an entry tension and $t_{4}$ an exit tension. The rolling load and rolling energy with phosphate pre-coating are a little less than those without phosphate precoating. Figure 4 shows the effect of phosphate precoating on rolling torque. The rolling torque of \#3 work roll increases abnormally in the case of $X_{3}=0$ with no phosphate pre-coating, while the rolling torque of \#3 work roll decreases and becomes almost the same as that of \#2 work roll in the case of $X_{3}=0$ with phosphate pre-coating. In the case of $X_{3}=0.2$ with phosphate pre-coating the rolling torques of \#2 to \#4 work rolls become nearly the same.

The lubrication in NCM rolling is severe because the slip ratio between a rolled material and the work rolls in NCM rolling is larger than that in normal rolling such as four-high or six-high rolling because of the different roll speed rolling. ${ }^{1,3)}$ In a strip-enveloping type NCM rolling particularly, heat scratch is apt to break out at the second and third passes as shown in Fig. 5, because of an insufficient supply of lubricant on the materials. Thus, in order to prevent heat scratch, the lubrication of phosphate pre-coating is used in addition to the $6 \%$ emulsion lubrication of fat oil. The phosphate is pre-coated on strip surfaces with an amount of 0.3 to $0.6 \mathrm{~g} / \mathrm{m}^{2}$ before rolling experiments.

Figure 6 shows the effect of phosphate pre-coating on the amount of steel powder adhering to the rolled strip surfaces in a strip-pulling-out type NCM rolling,
Fig. 3.

Effect of reduction in thickness on rolling load and rolling energy.

\begin{tabular}{|c|c|c|c|c|c|}
\hline \multicolumn{2}{|c|}{$\begin{array}{c}\text { Tension } \\
\left(\mathrm{kgf} / \mathrm{mm}^{2}\right)\end{array}$} & \multicolumn{2}{|c|}{$\begin{array}{l}\text { Roll speed } \\
\text { difference }\end{array}$} & \multirow{2}{*}{$\begin{array}{l}\text { Phos- } \\
\text { phate }\end{array}$} & \multirow{2}{*}{ Symbol } \\
\hline$t_{1}$ & $t_{4}$ & $X_{2}$ & $x_{3}$ & & \\
\hline 7.3 & 14.8 & 0.35 & 0 & No & -0 \\
\hline 5.1 & 14.9 & 0.35 & 0 & No & $-\Delta--$ \\
\hline 7.5 & 15.2 & 0.35 & 0 & Yes & $--\bullet$ \\
\hline
\end{tabular}

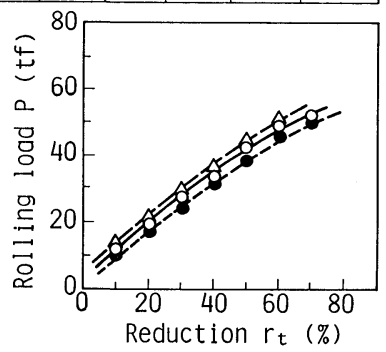

(a) Rolling load

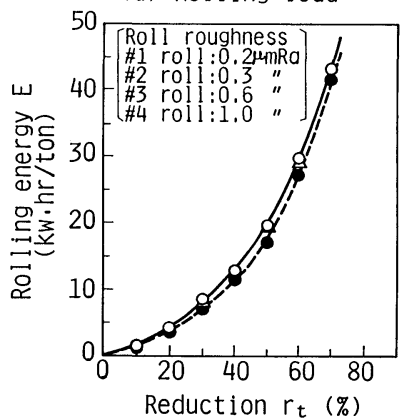

(b) Rolling energy

\begin{tabular}{|c|c|c|c|c|c|}
\hline \multicolumn{2}{|c|}{$\begin{array}{c}\text { Tension } \\
\left(\mathrm{kgf} / \mathrm{mm}^{2}\right)\end{array}$} & \multicolumn{2}{|c|}{$\begin{array}{l}\text { Roll speed } \\
\text { difference }\end{array}$} & \multirow{2}{*}{ phate } & \multirow{2}{*}{ Symbol } \\
\hline$t_{1}$ & $t_{4}$ & $X_{2}$ & $x_{3}$ & & \\
\hline 7.3 & 14.8 & 0.35 & 0 & No & \\
\hline 7.5 & 15.2 & 0.35 & 0 & Yes & $\cdots$ \\
\hline 7.4 & 15.2 & 0.35 & 0.2 & Yes & - - - \\
\hline
\end{tabular}

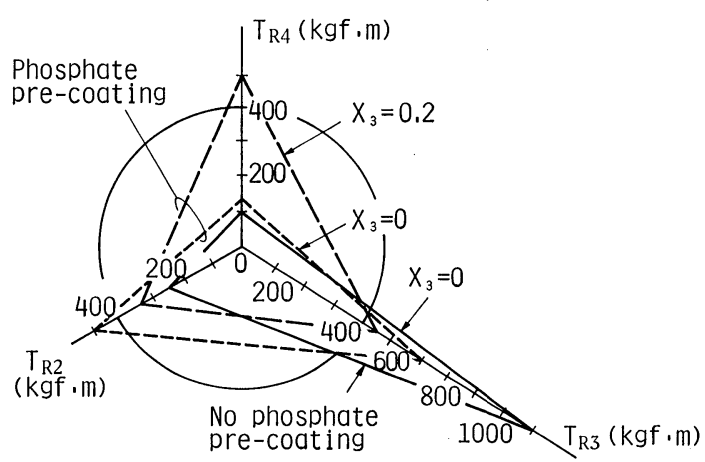

$T_{R 2}:$ Torque of \#2 roll Roll roughness

$T_{R 3}$ : Torque of \#3 roll

$T_{R 4}:$ Torque of \#4 roll

\#1 roll: $0.2 \mu \mathrm{mRa}$

\#2 roll: $0.3 \mu \mathrm{mRa}$

\#3 roll: $0.6 \mu \mathrm{mRa}$

Total reduction $r_{t}=70 \% \quad \# 4$ roll: $1.0 \mu \mathrm{mRa}$

Fig. 4. Effect of phosphate pre-coating on rolling torque.

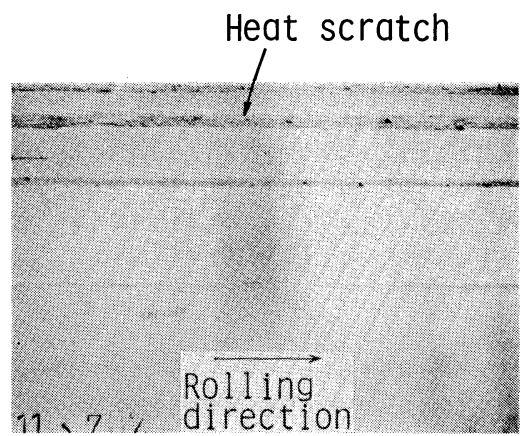

Fig. 5. Heat scratch caused on a surface of rolled strip in a strip-enveloping NGM (no phosphate pre-coating). 


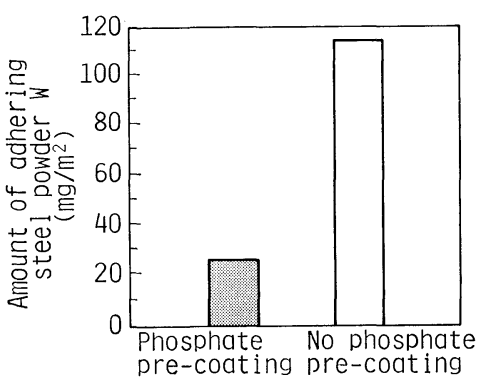

Strip-pulling-out NGM rolling, $r_{t}=70 \%$

Fig. 6.

Effect of phosphate pre-coating on the amount of adhering steel powder.

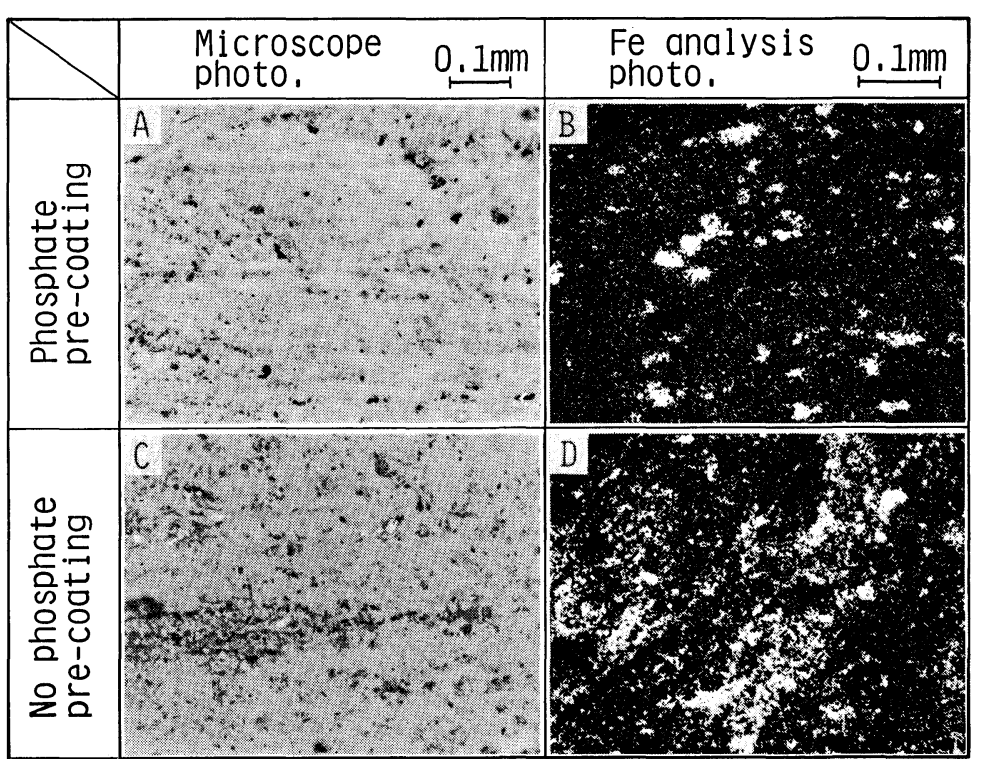

Strip-pulling-out NGM rolling, $r_{t}=70 \%$

Fig. 7. Comparison of steel powder formation between phosphate pre-coating and no phosphate pre-coating.

Table 2. Effect of phosphate pre-coating and strippulling-out on heat scratch on surfaces of rolled strip. $\left(r_{t}=70 \%\right)$

\begin{tabular}{|c|c|c|c|c|c|}
\hline & \multicolumn{3}{|c|}{ Rolling speed $V_{4} \mathrm{~m} / \mathrm{min}$} \\
\hline & & & 10 & 100 & 200 \\
\hline \multirow{2}{*}{\multicolumn{2}{|c|}{$\begin{array}{l}\text { No phosphate } \\
\text { pre-coating }\end{array}$}} & $\begin{array}{l}\text { envelop- } \\
\text { ing }\end{array}$ & $x$ & $x$ & $x$ \\
\hline & & $\begin{array}{l}\text { pulling- } \\
\text { out }\end{array}$ & 0 & $\underset{\text { KRolling i }}{\Delta}$ & $\begin{array}{c}\Delta \\
\text { stability }\end{array}$ \\
\hline \multirow{4}{*}{$\begin{array}{l}\text { Phosphate } \\
\text { pre-coating }\end{array}$} & \multirow{2}{*}{$\begin{array}{c}\text { about } \\
0.5 \\
\mathrm{~g} / \mathrm{m}^{2}\end{array}$} & $\begin{array}{l}\text { envelop- } \\
\text { ing }\end{array}$ & O & $x$ & $x$ \\
\hline & & $\begin{array}{l}\text { pulling- } \\
\text { out }\end{array}$ & $\mathrm{O}$ & O & O \\
\hline & \multirow{2}{*}{$\begin{array}{c}\text { about } \\
1.0 \\
\mathrm{~g} / \mathrm{m}^{2}\end{array}$} & $\begin{array}{l}\text { envelop- } \\
\text { ing }\end{array}$ & 0 & $x^{x}$ & $\times$ \\
\hline & & $\begin{array}{l}\text { pulling- } \\
\text { out }\end{array}$ & O & O & O \\
\hline
\end{tabular}

$\bigcirc:$ Good $\Delta:$ Some problems except heat scratch

$x$ : Heat scratch, dotted line shows anticipation

the case of a strip-pulling-out type with 4 nozzles and $105^{\circ} \mathrm{C}$ in the case of a strip-pulling-out type with 6 nozzles. These results suggest that a strip-pulling-out type NGM rolling is superior to a strip-enveloping type NGM rolling in roll cooling and that sufficient roll cooling is necessary even in a strip-pulling-out type NCM rolling.

\section{Automatic Gauge Controllability}

The automatic gauge control (AGG) system for NGM rolling, which consists of a decoupling AGG with constant volume flow and a monitor-type AGG with an X-ray gauge sensor, has been developed as shown in Fig. 10. The decoupling AGG with constant volume flow can control only the strip thickness at the third pass with the constant strip thickness at the first and second passes. The terms, $\alpha$ and $\beta$, in Fig. 10 are the control gains for the decoupling AGC. Figure 11 shows the results of AGC experiments made under the condition of a $60 \%$ reduction in thickness min after the rolling start indicated $160^{\circ} \mathrm{C}$ in the case of a strip-enveloping type with 4 nozzles, $135^{\circ} \mathrm{C}$ in 


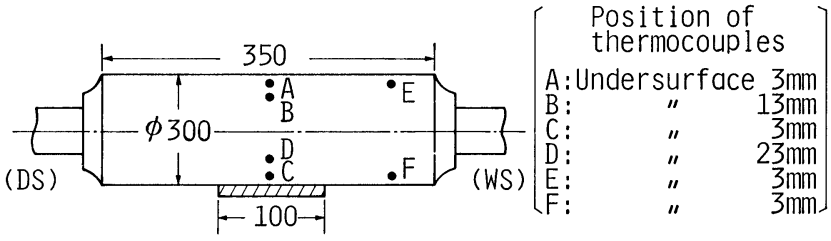

$(\bullet$ : thermocouple)

(a) Position of thermocouples

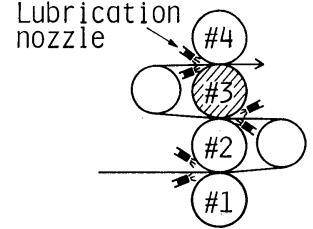

(A)

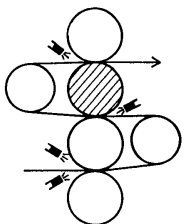

(B)

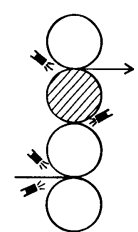

(C) (b) Rolling types and position of lubrication nozzles

Fig. 8. Method for measuring temperatures.

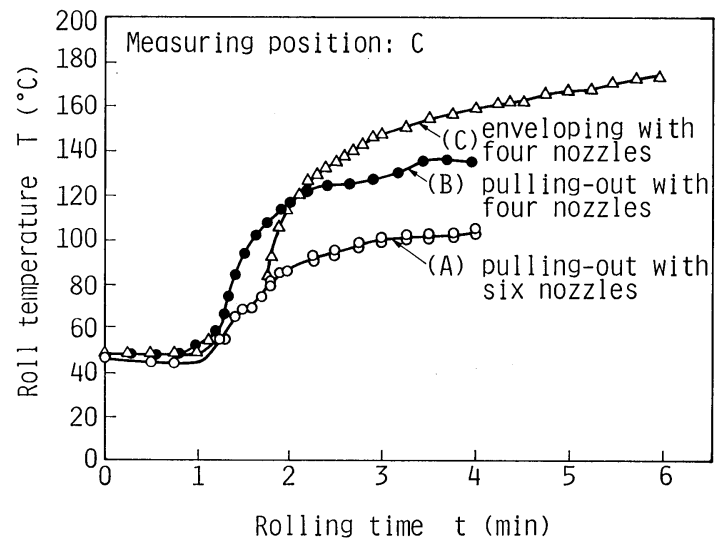

Supplied amount of lubrication

$\begin{array}{lll} & : & \text { about } 14 \mathrm{l} / \mathrm{min} \text { per nozzle } \\ \text { Rolling speed } & : & V_{4}=200 \mathrm{~m} / \mathrm{min} \\ \text { Reduction in thickness : } & r_{t}=70 \% \\ \text { Strip tensions } & : & t_{1}=7.0, t_{4}=15.7 \mathrm{kgf} / \mathrm{mm}^{2} \\ \text { Roll speed difference } & : & X_{2}=0.35, X_{3}=0.2 \\ \text { Other conditions are the same as those in Table } 1 .\end{array}$

Fig. 9. Effect of rolling types and the number of lubrication nozzles on roll temperatures at the position of $3 \mathrm{~mm}$ under the roll surface.

and a $70 \mathrm{~m} / \mathrm{min}$ rolling speed. The thickness deviation of a strip at the exit of the third pass indicated $\pm 9 \mu \mathrm{m}( \pm 0.98 \%)$ with no AGG system and $\pm 6 \mu \mathrm{m}$ $( \pm 0.65 \%)$ with the present AGC system, which assured the effectiveness of the AGG system in NCM rolling. The present decoupling AGC, as shown in Fig. 10, uses the hydraulic screwdown as the main actuator and the entry and exit tensions as the auxiliary actuators, but the roll speed difference at the second or third pass can be used for the decoupling AGG instead of the entry or exit tension.

Figure 12 is the relation between the periodic length of thickness variation in the initial strip and the thickness accuracy of the rolled strip, which was theoretically calculated in the case of a usual threestand tandem rolling with four-high mills and a strippulling-out type NCM rolling. This result shows that

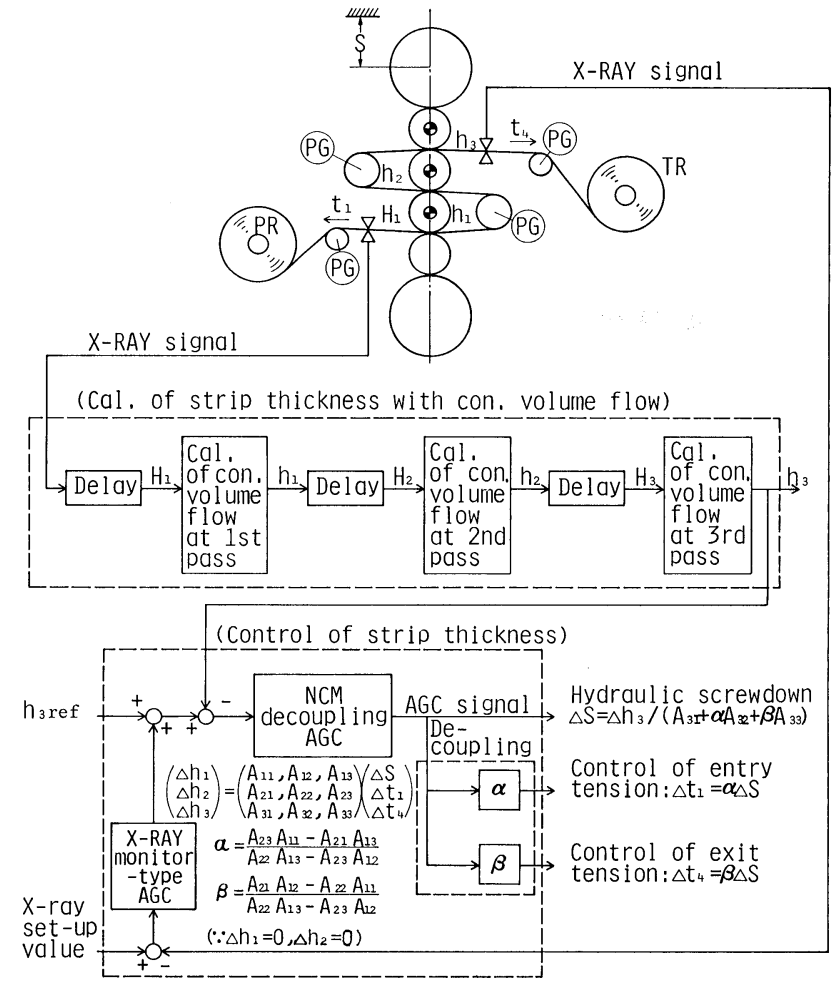

Fig. 10. Automatic gauge control system for NCM rolling.
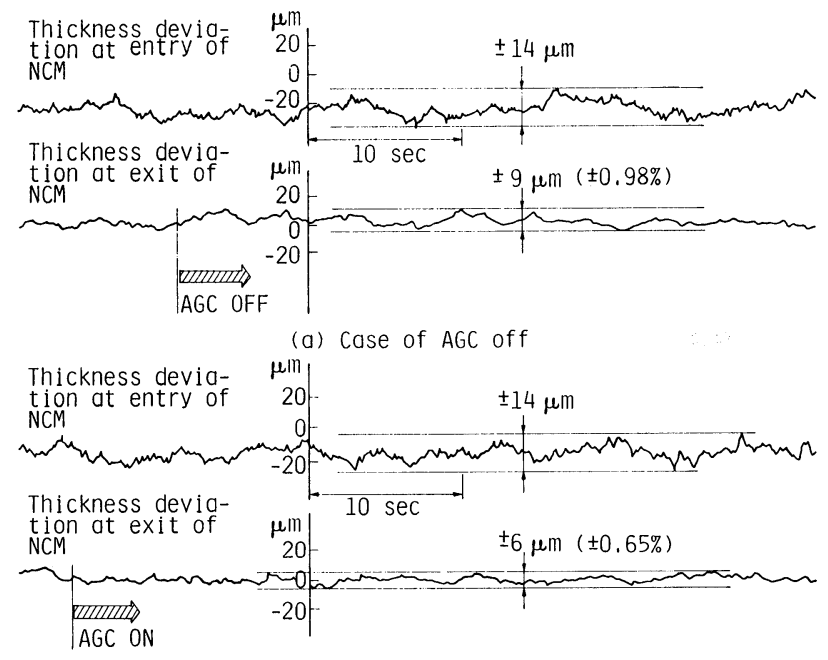

(b) Case of AGC on
Rolling speed
: $V_{4}=70 \mathrm{~m} / \mathrm{min}$
Reduction in thickness: $r_{t}=60 \%$
Strip tensions $\quad: t_{1}=7.0, t_{4}=15.0 \mathrm{kgf} / \mathrm{mm}^{2}$
Roll speed difference : $X_{2}=0.35, X_{3}=0.2$
Other conditions are the same as those in Table 1.

Fig. 11. Automatic gauge controllability in NGM rolling.

the automatic gauge controllability for NCM rolling is almost the same as that of the usual three-stand tandem rolling.

\section{Strip Shape Controllability}

The strip shape controllability was theoretically investigated with the shape analysis model, ${ }^{5)}$ as it is difficult to clarify the strip shape controllability of NCM rolling experimentally because of the restrictions on 


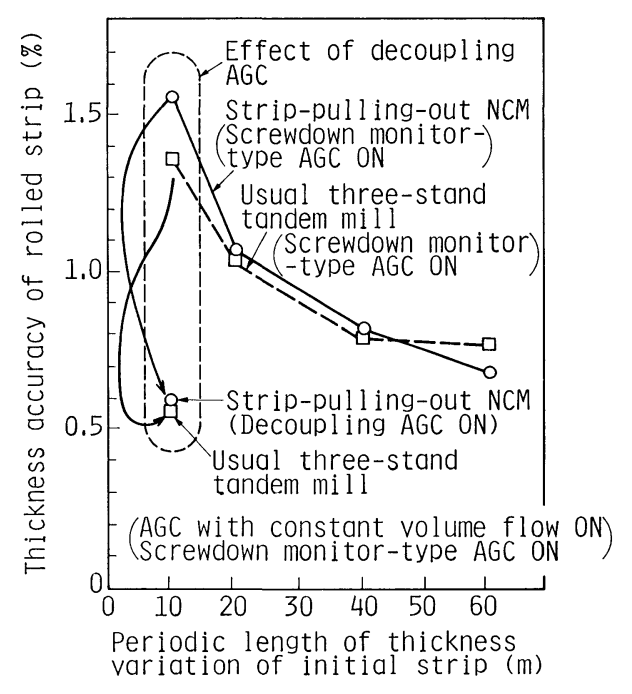

Fig. 12. Relation between periodic length of thickness variation of initial strip and thickness accuracy.

roll and strip sizes (refer to Table 1). The calculation of strip shape adopted a divided model ${ }^{6)}$ that divided a strip width and a roll length into about 40 elements, and a combination model that gave the rolling types with two-high rolls and one roll at the first and third passes and with one roll and one roll at the second pass. The entry tension at each pass was assumed to be independent of the strip shape, and the exit tension at each pass was assumed to affect the exit shape of the rolled strips. ${ }^{5}$ In this calculation of strip shape, the flatness distribution of a rolled strip was first calculated in the width direction, and then by approximating the flatness distribution to a regression equation of four degrees, the strip shape was evaluated in the $\left(\lambda_{2}, \lambda_{4}\right)$ coordinate, ${ }^{7)}$ where $\lambda_{2}$ is a flatness difference of the obtained regression equation of four degrees between the edge and center positions of strip width and $\lambda_{4}$ is that between the quarter and center positions.

Table 3 shows the calculation conditions. The NGM considered in the calculation was assumed to have four work rolls and two backup rolls with actual mill sizes and two roll benders at the first and third passes. The thermal crown of each work roll was 40 $\mu \mathrm{m}$, and the initial parabolic crowns were $40 \mu \mathrm{m}$ for the \#1 and \#3 work rolls and $100 \mu \mathrm{m}$ for the \#4 work roll. Figure 13 shows the calculation result, where the curve of strip shape controllability at the exit of the third pass is given as a bold dash-dot line. This result suggests that NGM rolling with the appropriate initial crowns on the work rolls and an adequate control of the roll benders enables good shape controllability.

\section{Characteristics of Edge-drop}

Figure 14 shows the comparison of ege-drop between NGM rolling and normal rolling. In the normal rolling one-pass rolling was performed three times with the same reductions and strip tensions as in each pass of NGM rolling with the upper and lower work rolls at the same speed. The thickness distribution
Table 3. Calculation conditions.

\begin{tabular}{|c|c|c|c|c|c|}
\hline 1. & \multicolumn{5}{|c|}{$\begin{array}{lll}\text { size } & \text { Work roll: } & \phi 500 \mathrm{~mm} \times 1400 \mathrm{~mm} l \\
& \text { Backup roll : } & \phi 1240 \mathrm{~mm} \times 1400 \mathrm{~mm} l\end{array}$} \\
\hline 2. & \multicolumn{5}{|c|}{ Distance between screwdowns : $2500 \mathrm{~mm} l$} \\
\hline 3. & \multicolumn{5}{|c|}{ Distance between roll benders : $2500 \mathrm{~mm} l$} \\
\hline 4. & \multicolumn{5}{|c|}{$\begin{array}{ll}\text { 1st pass } F_{1}: & +50 \sim-50 \mathrm{tf} / \text { chock } \\
\text { 3rd pass } F_{3}: & +50 \sim-50 \mathrm{tf} / \text { chock }\end{array}$} \\
\hline 5. & \multicolumn{5}{|c|}{ Initial crown of work roll : parabolic } \\
\hline 6. & \multicolumn{5}{|c|}{ Material: Mild carbon steel (SPGG) } \\
\hline 7. & \multirow{3}{*}{\multicolumn{5}{|c|}{ Strip size Thickness: $2.3 \mathrm{~mm}$}} \\
\hline & & & & & \\
\hline & & & & & \\
\hline 8. & \multirow{2}{*}{\multicolumn{5}{|c|}{$\begin{array}{l}\text { Total reduction in thickness: } 60 \% \\
\text { Reduction, tension and friction coefficient at each pass }\end{array}$}} \\
\hline & & & & & \\
\hline & & & \multicolumn{3}{|c|}{ Rolling schedule } \\
\hline & & & 1st pass & 2nd pass & 3rd pass \\
\hline & Reductior & & $28.8 \%$ & 24.5 & 25.5 \\
\hline & \multirow{2}{*}{$\begin{array}{c}\text { Thick- } \\
\text { ness }\end{array}$} & Entry & $2.3 \mathrm{~mm}$ & 1.64 & 1.24 \\
\hline & & Exit & $1.64 \mathrm{~mm}$ & 1.24 & 0.92 \\
\hline & \multirow{2}{*}{ Tension } & Entry & $\begin{array}{l}13.8 \mathrm{tf} \\
\left(5.0 \mathrm{kgf} / \mathrm{mm}^{2}\right)\end{array}$ & $\begin{array}{c}21.2 \\
(10.8)\end{array}$ & $\begin{array}{c}21.8 \\
(14.7)\end{array}$ \\
\hline & & Exit & $\begin{array}{l}21.2 \mathrm{tf} \\
\left(10.8 \mathrm{kgf} / \mathrm{mm}^{2}\right)\end{array}$ & $\begin{array}{l}21.8 \\
(14.7)\end{array}$ & $\begin{array}{c}16.6 \\
(15.0)\end{array}$ \\
\hline & \multicolumn{2}{|c|}{$\begin{array}{l}\text { Friction coeffi- } \\
\text { cient }\end{array}$} & 0.045 & 0.055 & 0.065 \\
\hline & \multicolumn{2}{|c|}{ Rolling load } & $\begin{array}{l}W=800 \mathrm{~mm}: \\
W=1200 \mathrm{~mm}:\end{array}$ & $\begin{array}{r}700 \mathrm{tf} \\
1050 \mathrm{tf}\end{array}$ & \\
\hline
\end{tabular}

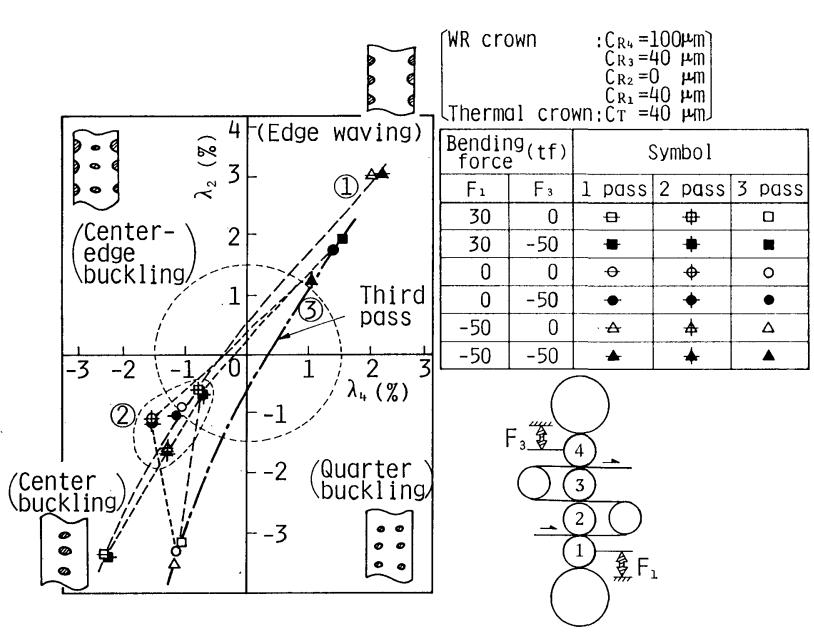

$F_{1}$ : Work roll bender at 1 st pass

$F_{3}$ : Work roll bender at 3 rd pass

Fig. 13. Strip shape controllability in NGM rolling.

was measured at each pass in both the NGM and normal rolling. The edge-drop was defined as a thickness difference between two positions of 20 and $5 \mathrm{~mm}$ from a strip edge. The edge-drop in NGM rolling was less than in the normal rolling at the exit of each pass, and in particular the edge-drop in NGM rolling was 30 to $50 \%$ less than in the normal rolling at the exit of the third pass. The decreasing of edgedrop in NCM rolling is due to the different roll speed rolling, ${ }^{3)}$ where the peripheral speed of the upper work roll is different from that of the lower work roll. 


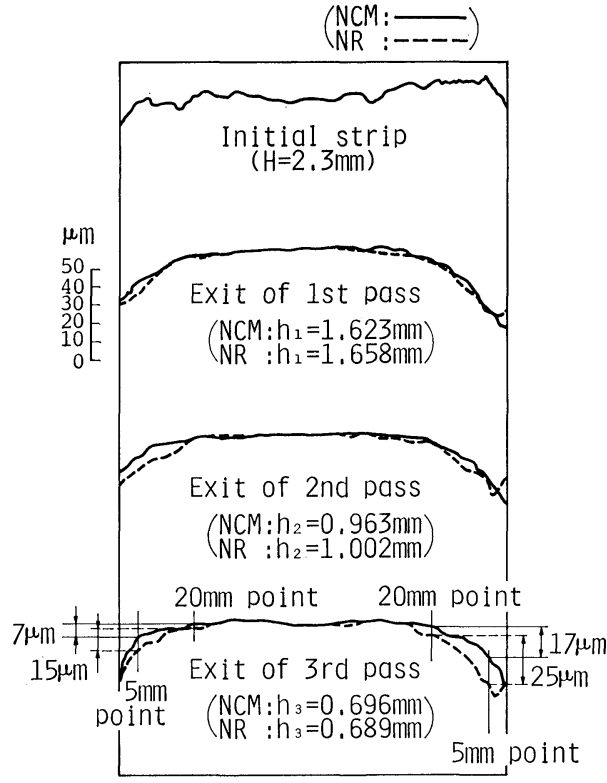

Rolling conditions

Roll diameter (NCM, NR): $\quad \phi 300 \mathrm{~mm}$

Initial strip thickness $\quad: \quad 2.3 \mathrm{~mm}$

Strip width $\quad: 100 \mathrm{~mm}$

(1) NGM

$r_{t}=70 \%, P=50 \mathrm{tf}, X_{2}=0.35, X_{3}=0.2$

$t_{1}=5, t_{2}=17, t_{3}=21, t_{4}=16 \mathrm{kgf} / \mathrm{mm}^{2}$

(2) $\mathrm{NR}$

$r_{t}=70 \%$

1st pass: $P_{1}=55 \mathrm{tf}, \sigma_{b}=5, \quad \sigma_{f}=16 \mathrm{kgf} / \mathrm{mm}^{2}$

2nd pass: $P_{2}=58 \mathrm{tf}, \sigma_{b}=16, \sigma_{f}=13 \mathrm{kgf} / \mathrm{mm}^{2}$

3rd pass: $\quad P_{3}=56 \mathrm{tf}, \sigma_{b}=13, \sigma_{f}=15 \mathrm{kgf} / \mathrm{mm}^{2}$

Fig. 14. Comparison of edge-drop between NCM rolling and normal rolling (NR).

\section{Comparison of NCM Rolling Types}

According to the characteristics of NCM rolling described in this paper, the comparison between a strippulling-out type and a strip-enveloping type for NCM rolling was shown in Table 4. It seems that there is no significant difference between a strip-pulling-out type and a strip-enveloping type in high reduction per one stand, automatic gauge controllability, strip shape controllability and edge-drop. However, heat scratch is apt to break out in a strip-enveloping type, while a strip-pulling-out type causes no heat scratch. Also a strip-pulling-out type is superior to a strip-enveloping type in roll cooling. Therefore, a strip-pulling-out type NGM rolling is more suitable than a strip-enveloping type NCM rolling.

\section{Conclusion}

A new compact multi-reduction mill (NCM), which can substitute one stand for two or three stands in a cold tandem mill, has been developed. This new mill is based on a three-pass rolling in one stand and allows a $70 \%$ reduction in thickness in the cold rolling of mild carbon steel. The following is a summary of the results.

(1) The lubrication of phosphate pre-coating is used in addition to an emulsion lubrication, because the slip ratio between a rolled material and the work
Table 4. Comparison of NCM rolling types.

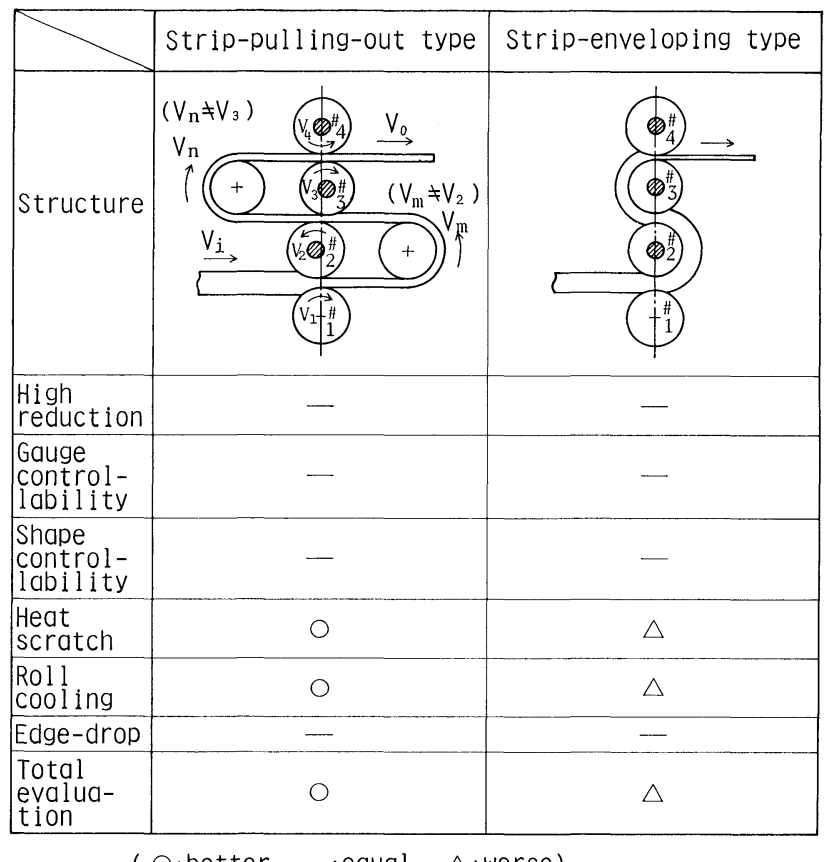

rolls in NGM rolling is larger than that in normal rolling such as in four-high or six-high rolling. The rolling load and rolling energy with phosphate precoating are a little less than those with no phosphate pre-coating.

(2) The phosphate pre-coating shows a major effect on the prevention of steel powder formation.

(3) A strip-pulling-out type NCM rolling with phosphate pre-coating causes no heat scratch and gives stable rolling at a rolling speed of $200 \mathrm{~m} / \mathrm{min}$ with a $70 \%$ reduction in thickness.

(4) A strip-pulling-out type NGM rolling is superior to a strip-enveloping type in roll cooling.

(5) The automatic gauge control (AGC) system for NCM rolling, which consists of a decoupling AGC with constant volume flow and a monitor-type AGC with an X-ray gauge sensor, has been developed. The rolling experiments and theoretical calculations showed this new AGG system to have effective automatic gauge controllability.

(6) The theoretical calculations of strip shape suggested that NCM rolling with the appropriate initial crowns on the work rolls and an adequate control of the roll benders enabled good shape controllability.

(7) At the exit of the third pass the edge-drop of NGM rolling is 30 to $50 \%$ less than that of a normal rolling with three one-pass rollings.

(8) Therefore, a strip-pulling-out type NCM rolling is more suitable than a strip-enveloping type NGM rolling and shows excellent rolling characteristics as a compact high-reduction mill.

\section{Acknowledgements}

The authors are grateful to Messrs. S. Sonoda and M. Iwamoto, Technical Research Laboratory, Nippon Parkerizing Co., Ltd. for their helpful cooperation with phosphate pre-coating. 


\section{REFERENCES}

1) K. Miyasaka, S. Koide, H. Shiozaki, H. Yamamoto, T. Iura, T. Kawanami and A. Tanaka: Trans. Iron Steel Inst. Jpn., 28 (1988), 498.

2) H. Yamamoto, K. Nakajima and T. Kawanami: J. Jpn. Soc. Technol. Plast., 25 (1984), 994.

3) H. Shiozaki, S. Shinya, M. Mikami, T. Arimura, K. Okado and H. Hujita: The Proceedings of the 1978 Japanese Spring Conference for the Technology of Plasticity, Japan Soc. Technol. Plast., Tokyo, (1978), 33.

4) K. Murata, H. Morise, T. Komatsu, S. Shida, Y. Sano and
S. Hashimoto: Tetsu-to-Hagané, 68 (1982), S349.

5) H. Yamamoto and T. Kawanami: The Proceedings of the 1984 Japanese Spring Conference for the Technology of Plasticity, Japan Soc. Technol. Plast., Tokyo, (1984), 13.

6) K. N. Shohet and N. A. Townsend: J. Iron Steel Inst., 190 (1971), 769.

7) R. Toda, S. Matsuka, S. Kitajima and N. Inoue: The Proceedings of the 29th Japanese Joint Conference for the Technology of Plasticity, Japan Soc. Technol. Plast., Tokyo, (1978), 97. 